DOI: http://dx.doi.org/10.18203/2320-1770.ijrcog20175278

Original Research Article

\title{
Laparoscopy: the tool for infertility
}

\author{
Neelima P. Shah ${ }^{1 *}$, Prashant D. Shah ${ }^{2}$ \\ ${ }^{1}$ Department of Obstetrics and Gynecology, D. Y. Patil Medical College, Kolhapur, Maharashtra, India \\ ${ }^{2}$ Department of Obstetrics and Gynecology, Krishna Institute of Medical Sciences, Karad, Maharashtra, India
}

Received: 08 October 2017

Accepted: 11 November 2017

\section{*Correspondence:}

Dr. Neelima P. Shah,

E-mail: neelimapshah@gmail.com

Copyright: () the author(s), publisher and licensee Medip Academy. This is an open-access article distributed under the terms of the Creative Commons Attribution Non-Commercial License, which permits unrestricted non-commercial use, distribution, and reproduction in any medium, provided the original work is properly cited.

\begin{abstract}
Background: Most of the healthy couples conceive within a year after marriage. The infertility patients have become important part of clinical practice. Diagnostic and therapeutic Laparoscopy plays major role in the management of these cases. We investigated hale 50 infertile women with laparoscopy. This study was undertaken to ascertain the diagnostic and therapeutic role of Laparoscopy in female infertility.

Methods: We evaluated 50 couples having infertility. The cases of primary and secondary infertility were evaluated. The laparoscopy was done under general anaesthesia. The pelvic organs were examined, and tubal patency was tested with chromo-perturbation by using Methylene blue dye. The findings were noted. The therapeutic intervention was done in the cases where it was necessary.

Results: Total 50 cases of infertility were studied. Thirty were of primary infertility and 20 were of secondary infertility. The patients with primary infertility were younger with mean age of 20 years. The duration of infertility ranged from 1.5 to 8 years. We detected total $21(42 \%)$ patients with ovarian pathology, $5(10 \%)$ with tubal, four $(8 \%)$ with peritoneal factor $3(6 \%)$ with endometriosis. One patient had uterine fibroid and $16(32 \%)$ cases had normal laparoscopic findings.

Conclusion: This study supported the diagnostic and therapeutic value of laparoscopy in managing infertile women. It helped in detection of pelvic pathology. It also helped to plan further management in the form of IUI or IVF.
\end{abstract}

Keywords: Infertility, Laparoscopy, Pelvic

\section{INTRODUCTION}

Most of the healthy young couples conceive within one year after marriage. Approximately $10-15 \%$ of couples have infertility. The diagnosis and management of infertility has become important part of clinical practice. In the etiology of infertility $40-55 \%$ couples have female factors and $30-40 \%$ of couples have male factors as contributing factor. ${ }^{1}$ In $10 \%$ of the cases, both the partners are affected while $10 \%$ are the cases of unexplained infertility. The causes of infertility are ovarian dysfunction, tubal diseases, endometriosis, uterine or cervical factors and male factor.
In last few decades the evaluation and treatment of infertility has changed a lot. Hysterosalpingography helps to reveal the tubal block. However, pelvic factors other than tubal block are not diagnosed by Hysterosalpingography.

Sakar MN et al compared the tuboperitoneal factors of infertile woman by hysterosalpingography and laparoscopy in their cohort study. $^{2} 82$ cases were retrospectively evaluated by laparoscopy which was done 3 months after HSG. They concluded that laparoscopy was superior method for studying tubal and pelvic pathologies while evaluating infertile couple. However, 
HSG is economical and suitable method for testing tubal patency. Laparoscopy is an appropriate method for examining the external part of the tube, fimbriae, relation of tube and ovary, endometriosis, adhesions, etc. Therefore, these two methods are not alternative but complementary to each other. Boundhran $\mathrm{K}$ et al evaluated 200 cases of infertility by hysterolaparoscopy and reported that diagnostic laparoscopy after several failed cycles of ovulation induction enabled to detect pelvic pathology amenable to treatment. ${ }^{3}$

A Cochrane review has shown that laparoscopic ovarian drilling in clomiphene resistant polycystic ovarian syndrome is as effective as gonadotropin treatment and with lower multiple pregnancy rate. ${ }^{4}$

The objective of this study was undertaken to ascertain the diagnostic and therapeutic role of laparoscopy in patients of female infertility.

\section{METHODS}

This study was performed during the period from June 2014 to December 2015. We have evaluated 50 couples having infertility. Detail history was taken by using questionnaire. The case of primary and secondary infertility both were included. Written consent of the patient and relatives was taken.

The patients having heart disease, chromosomal disorders, documented uterine anomalies, documented genital tuberculosis were excluded from the study. Those patients who had contraindications for laparoscopic procedures like generalized peritonitis, Hernia, large pelvic masses were also excluded from the study.

Laparoscopy was done under general anesthesia. The lithotomy position was given to the patient. A small incision was made in infraumbilical fold. Pneumoperitoneum was done with Veres needle. Confirmation of correct placement of the needle was done. $\mathrm{CO}_{2}$ gas was used to inflate the peritoneal cavity at the rate of $1 \mathrm{~L} /$ minute. A total of $2-3 \mathrm{~L}$ of gas was required. Intraperitoneal pressure was maintained around 10-15 $\mathrm{mm}$ of $\mathrm{Hg}$.

Adequate insufflation was confirmed by obliteration of liver dullness and uniform abdominal distension. The 10 $\mathrm{mm}$ trochar and cannula was introduced through the infraumbilical incision after elevating the abdominal wall. The tip of trochar was directed towards the sacrum. Once the peritoneal cavity was entered, trochar was removed and the laparoscope was inserted. The light source was connected using fiberoptic light source. The camera was connected to the laparoscope. The peritoneal cavity and the intraperitoneal structures were inspected thoroughly. A second port was made using $5 \mathrm{~mm}$ trochar and cannula. This second port was used for the instruments like probe, grasper, Bowel holding forceps, etc. Tubal patency was tested by chromopertubation using methylene blue dye which was pushed in uterine cavity using HSG cannula. All the data were computerized for analysis using MS-Excel system.

The different quantitative variables are expressed in terms of mean \pm SD like duration of infertility, age of infertility and the different qualitative variables are expressed in terms of percentage. The chi-square test is used to compare the percentage. $(\mathrm{P}<0.05)$ is considered to be statistically significant. Chi-square p-value is calculated in Graph pad quick cal software.

\section{RESULTS}

We studied total of 50 patient of female infertility. Out of 50 cases $30(60 \%)$ were of primary infertility and 20 (40\%) cases were of secondary infertility. Patients of primary infertility were younger compared to secondary infertility. They were in the age group of 21-25 years. while those of secondary infertility were in the age group of 26 to 30 years. Mean age of the patient of primary infertility was 26 years while that of secondary infertility was 29 years. The duration of infertility ranged from 1.5 years to 8 years. Maximum numbers of cases had duration between 4 years to 7 years. In primary infertility most of the patients were from age group of 21 years to 25 years i.e. 20 cases $(66.6 \%)$ and in secondary infertility it was 24 years to 30 years i.e. 14 cases $(70 \%)$. In the 30 cases of primary infertility we detected 16 cases with ovarian pathology. Only 2 cases had endometriosis while 12 cases were normal.

Table 1: Causative factors of infertility.

\begin{tabular}{|llll|}
\hline $\begin{array}{l}\text { Causative } \\
\text { factor }\end{array}$ & $\begin{array}{l}\text { Primary } \\
\text { infertility }\end{array}$ & $\begin{array}{l}\text { Secondary } \\
\text { infertility }\end{array}$ & Total \\
\hline Ovarian & 16 & 5 & $21(42 \%)$ \\
\hline Tubal & 0 & 5 & $5(10 \%)$ \\
\hline Peritoneal & 0 & 4 & $4(8 \%)$ \\
\hline Endometriosis & 2 & 1 & $3(6 \%)$ \\
\hline Uterine & 0 & 1 & $1(2 \%)$ \\
\hline Normal & 12 & 4 & $16(32 \%)$ \\
\hline Total & 30 & 20 & 50 \\
\hline & $\mathrm{P}=0.0055$ & $\mathrm{P}=0.55$ & \\
\hline
\end{tabular}

In 20 cases of secondary infertility we detected 5 cases each having ovarian and tubal pathology. 4 cases had adhesions in pouch of Douglas. one case was having uterine fibroid.

Out of all 50 cases, we found ovarian factor of infertility to be commonest i.e. $21(42 \%)$ cases. $15(20 \%)$ cases had PCOD, $4(8 \%)$ cases had simple cysts in ovary, $2(4 \%)$ cases had chocolate cyst. Out of $5(10 \%)$ cases of tubal factor which were detected in secondary infertility group, $4(8 \%)$ cases had hydrosalphinx and one case was of cornual block.

Four cases $(8 \%)$ had peritoneal adhesions in the pouch of Douglas. History of pelvic inflammatory disease was 
present in those cases. Out of 3 cases of endometriosis, one was having chocolate cyst, while two had mild endometriosis. One patient of secondary infertility was detected to have 2 fibroids. Out of total 50 cases of infertility we did not find any abnormality in $16(32 \%)$ cases. Out of those $6(16 \%)$ cases had male factor. In 10 (20\%) cases we could not find any abnormality those were the cases of unexplained infertility.

The therapeutic intervention was done in the cases where the pathological lesions were detected. Ovarian drilling was done in 15 cases of PCOD. Chocolate cyst excision was done. Endometriotic spots were fulgurated in 3 cases. Adhesiolysis was done in 4 cases. Tubal cannulation was done in the case of cornual block. Those with normal finding and having male factor were referred for intrauterine insemination. Out of 15 cases of PCOD, where ovarian drilling was done, 5 cases conceived in next cycle. Out of the patient of endometriosis where fulguration was done, one conceived after 2 cycles. The one with tubal cannulation was lost to follow up.

\section{DISCUSSION}

This study was done to ascertain the role of diagnostic and therapeutic laparoscopy in infertility. Total fifty women underwent laparoscopy in our study. The mean age of primary infertility patients was 26 years and that of secondary infertility was 29 years. This finding was similar to Boricha YG et al, where it was 26.5 and 30 years respectively. ${ }^{5}$ The primary infertility patients were younger compared to secondary infertility patients. The duration of infertility was 1.5 to 8 years in the present study. It was 4 to 7 years in Boricha et al study. ${ }^{5}$

In this study we found ovarian factor to be more common i.e. $42 \%$. Boricha et al also reported the ovarian factor to be the most common. ${ }^{5}$ However, Sainath et al found tubal factor to be more common in their study. ${ }^{6}$ Kanal P et al found pelvic pathology in almost $70 \%$ of cases. ${ }^{7}$

Fifteen cases had PCOD and four cases had simple ovarian cyst. In 2 cases chocolate cyst was found. Ovarian drilling was carried out in PCOD cases. Those were the cases who had undergone clomiphene citrate treatment. In the present study tubal factor was found only in $10 \%$ of cases. All these cases were from the secondary infertility group. Four of them had hydrosalphinx while one was with cornual block. Many studies (Farhi et al, Farqnhan $\mathrm{C}$ et al, Al-Ojam $\mathrm{H}$ et al have recorded reduction in serum $\mathrm{LH}$ after ovarian drilling. ${ }^{8,49}$ Gary et al observed the improvement in symptoms with laparoscopic treatment of endometriosis. ${ }^{10}$

We found adhesions in pouch of Douglas in 4 cases (8\%). One case was found to have uterine fibroid. Normal laparoscopic findings were observed in sixteen (32\%) cases. Three of our patients were observed to have mild to moderate endometriosis. Therapeutic intervention in the form of fulgeration was done in those cases.

Thus, the present study supported the diagnostic value of laparoscopy in infertile patients. Boricha et al stated that the exclusion of bilateral tubal pathology could avoid IVF treatment. $^{5}$ They recommended diagnostic laparoscopy prior to making decision of IUI or IVF. Tenahatoe et al, investigated the additional value of laparoscopy for planning further treatment. ${ }^{11}$ This study proved the importance of laparoscopy for correct diagnosis especially in endometriosis and peritoneal factor which were not diagnosed prior to laparoscopy.

\section{CONCLUSION}

The laproscopy plays an important role in diagnosis and management of infertility. It is a gold standard for diagnosing tubal and peritoneal factors, endometriosis and adhesions because no other imaging technique can give the similar information. Exclusion of bilateral tubal pathology can avoid IVF. Similarly, detaching, similarly finding of tubal pathology will lead to early referral for IVF. It has great role in diagnosis and treatment of endometriosis.

\section{ACKNOWLEDGMENTS}

The authors are thankful to Dr. Arvind Gulbake (Coordinator, R and D, CIR, DYPU, Kolhapur) for editing and drafting of manuscript.

\section{Funding: No funding sources}

Conflict of interest: None declared

Ethical approval: The study was approved by the Institutional Ethics Committee

\section{REFERENCES}

1. Speroff L, Marc AF. Female Infertility. Clinical Gynecologic Endocrinology and Infertility. $7^{\text {th }}$ ed. Lippicott Williams and Wilkins; 2005:1013-1068.

2. Sakar MN, Gul T, Atay AE, Celik Y. Comparison of hysterosalpingography and laparoscopy in the evaluation of infertile women. Saudi Med J. 2008;29(9):1315-8.

3. Boudhraa K, Jellouli MA, Kassaoui O, Ben AN, Ouerhani R, Triki A, et al. Role of the hysteroscopy and laparoscopy in management of the female infertility: about 200 cases. La Tunisie Medicale. 2009;87(1):55-60.

4. Farquhar C, Lilford RJ, Marjoribanks J, Vandekerckhove P. Laparoscopic 'drilling' by diathermy or laser for ovulation induction in anovulatory polycystic ovary syndrome. Cochrane Database Syst Rev. 2007;(3):CD001122.

5. Boricha YG, Sharma RK, Boricha BG, Mhapankar S, Chaterjee A, Narshetty J. Laparoscopy in 50 infertile couples: prospective study. Int J Med Clin Res. 2011;2:63-6. 
6. Sailatha R, Sathiya S, Famida AM, Vijayalakshmi K, Renuka S, Misha P. Role of laparoscopy in investigation of female infertility: a retrospective study of 50 cases. J Evolution Med Dental Sci. 2014;3(28):7795-800.

7. Kanal P, Sharma S. Study of primary infertility in females by diagnostic laparoscopy. Internet $\mathbf{J}$ Med Update. 2006 July-Dec;1(2):7-9.

8. Farhi J, Soule S, Jacobs HS. Effect of laparoscopic ovarian electrocautery on ovarian response and outcome of treatment with gonadotropins in clomiphene citrate-resistant patients with polycystic ovary syndrome. Fertility and sterility. 1995;64(5):930-5.

9. Al-Ojain EH. Laparoscopic ovarian drilling for polycystic ovarian syndrome in Clomiphene citrate- resistant women with anovulatory infertility. Bahrain Medical Bulletin. 2003;25(2):58-63.

10. Garry R, Clayton R. Hawe J. The effect of endometriosis and its radical laparoscopic excision on quality of life indicators. Br J Obstet Gynaceol. 2000;107(1):44-5.

11. Talib W, Ikram M, Hafeez M, Saeed M. Infertile female; laparoscopic evaluation. Prof Med J. 2007;14(4):562-6.

Cite this article as: Shah NP, Shah PD. Laparoscopy: the tool for infertility. Int J Reprod Contracept Obstet Gynecol 2017;6:5544-7. 